\title{
RAPID URINE TRYPSINOGEN-2 DIPSTICK ASSAY TO DIAGNOSE ACUTE PANCREATITIS IN EMERGENCY SETUP
}

\section{Hepatobiliary Surgery}

Shankar.S

Kolandasamy.C

Srinivasan.U.P

Naganath babu

O.L.*
Resident, Institute of Surgical Gastroenterology, Madras Medical College and Rajiv Gandhi Government General Hospital, Chennai, India.

Institute of Surgical Gastroenterology, Madras medical college Rajiv Gandhi Government General Hospital, Chennai, Tamilnadu, India.

Institute of Surgical Gastroenterology, Madras medical college Rajiv Gandhi Government General Hospital, Chennai, Tamilnadu, India.

M.Ch., FRCS(Edin), Director and Professor, Institute of Surgical Gastroenterology, Madras Medical College and Rajiv Gandhi Government General Hospital, Chennai, India. *Corresponding Author

\section{ABSTRACT}

Background: Early diagnosis of acute pancreatitis remains a challenge in emergency set up. The early management results in better outcomes but none of the available investigations were rapid and accurate to guide the management in these patients. Hence in suspected cases of acute pancreatitis, the urinary trypsinogen 2 dipstick assay can be used to diagnose them at the earliest in the Emergency setup. The purpose of this study is to determine the accuracy of urine trypsinogen 2 assay in diagnosing acute pancreatitis.

Methods: The patients presenting with symptoms consistent with acute pancreatitis to the emergency department, at a tertiary care hospital in Southern India between November 2018 to November 2019 were included in a prospective observational study after obtaining Institutional ethical committee clearance. In addition to the routine investigations done in cases of acute abdomen, patients underwent urine trypsinogen 2 dipstick test. Sensitivity, specificity, positive predictive value (PPV), negative predictive value (NPV) were calculated. Results were compared.

Results: A total of 50 cases were included in the study. The urine trypsinogen 2 dipstick test was positive in 35 of 37 patients with acute pancreatitis (sensitivity, 94.59\%) and in none of 13 patients with abdominal pain but without any evidence of acute pancreatitis (specificity, 100\%). The diagnostic accuracy of the urine trypsinogen 2 dipstick test was $96 \%$ in this study higher than other conventional laboratory investigations.

Conclusion: This study shows that the dipstick test has high diagnostic accuracy and can be considered for regular use for diagnosing pancreatitis along with the conventional methods.

\section{KEYWORDS}

Acute pancreatitis, Contrast enhanced computed tomography, Dipstick test, Serum amylase, Urine trypsinogen

\section{INTRODUCTION:}

Acute pancreatitis is an acute inflammatory condition of the pancreas leading to injury or destruction of acinar components and clinically characterized by abdominal pain and elevated levels of pancreatic enzymes in blood ${ }^{1}$.The clinical spectrum is as diverse as its etiopathogenesis. Acute pancreatitis can range from relatively mild to severe forms with potentially life-threatening complications ${ }^{1}$.

Acute pancreatitis with its associated complications both local and systemic complications leading to mortality, ranges from approximately $1 \%$ to $20 \%$ in mild to severe cases respectively ${ }^{2}$. The spectrum of disease and its complications follows a biphasic distribution. Early death is usually from the development of severe and irreversible multi-organ dysfunction from systemic inflammatory response syndrome from local complications, whereas late death occurs in the latter phase of the illness, from multi-organ failure as the end result of sepsis and its sequelae $\mathrm{e}^{1,3}$. In the clinical setting, acute pancreatitis is an evolving, dynamic condition and that disease severity may change during the course of disease. Hence early identification of patients on admission allows for aggressive treatment.

The diagnosis of Acute pancreatitis based on the clinical presentation of the patient is challenging as its clinical presentation is similar to number of other illnesses. The standard criteria for diagnosing AP includes (1) abdominal pain consistent with pancreatitis, (2) serum lipase and/or amylase $\geq 3$ times the upper limit of normal, and (3) characteristic findings from abdominal imaging ${ }^{1}$

The availability, rapidity and diagnostic accuracy of the conventional investigations are the factors posing difficulty in early diagnosis and management of acute pancreatitis in emergency setup especially in peripheral hospitals ${ }^{4,5}$

Trypsinogen is a $25-\mathrm{KD}$ pancreatic proteinase. The two main isoenzymes, (cationic) trypsinogen-1 and (anionic) trypsinogen-2, are secreted at high concentrations into pancreatic fluid, but a small proportion escapes into the circulation. Because of their relatively small size, trypsinogens are readily filtered through the glomeruli. For unknown reasons, the tubular reabsorption of trypsinogen-2 is lower than that of trypsinogen-1, and consequently, the urinary concentration of trypsinogen-2 is higher. In acute pancreatitis trypsinogen-2 levels increase rapidly both in serum and urine ${ }^{6}$. Hence, Measurement of urine trypsinogen 2 is considered useful in diagnosing acute pancreatitis. The dipstick test based on immunochromatographic measurement of trypsinogen-2 uses two new monoclonal antibodies, now commercially available (Medix Biochemica, Kaunianen, Finland) and has proven to be highly sensitive and specific ${ }^{6}$. The results of the dipstick test were compared with those of the conventional tests in diagnosing acute pancreatitis in this study.

\section{MATERIALS \& METHODS:}

\section{Patients:}

The study was conducted prospectively in the fifty patients admitted to the Emergency Department of the Rajiv Gandhi Government General Hospital with the symptoms suspicious of acute pancreatitis between November 2018 to November 2019. All adult, non-pregnant, normorenal patients presenting to emergency department, with acute upper abdominal pain with suspected pancreatitis were eligible to be included in the study. The patients already known cases of pancreatitis on follow up were excluded. The patients who were willing to provide written informed consent and a urine sample in addition to routine investigations for diagnosis of AP were included in the study. The diagnosis of pancreatitis was established based on the clinical findings, ultrasonography, contrast enhanced computed tomography of abdomen, serum amylase and lipase values. The control group comprised patients admitted to the Emergency Department with upper abdominal pain who were diagnosed later as acute cholecystitis, hollow viscus perforation, and mesenteric ischemia. The diagnosis of acute pancreatitis was based on clinical features such as epigastric pain with radiation to back, nausea, and vomiting with elevated serum amylase and serum lipase levels, and characteristic imaging findings in abdominal ultrasonography or contrast-enhanced computed tomography of abdomen according to the Atlanta criteria ${ }^{1}$

\section{Laboratory and Imaging Methods:}

All the patients included in the study underwent routine evaluation which includes clinical examination, laboratory assessment of haematological parameters, liver function tests, kidney function tests, 
serum amylase, serum lipase and imaging by abdominal ultrasonography or contrast-enhanced computed tomography (CECT) of abdomen. In addition to these investigations, a urine sample was collected from each patient to test for trypsinogen-2, using the Urine Trypsinogen 2 (Actim Pancreatitis; Medix Biochemica) test strip.

Serum amylase/lipase was considered positive for acute pancreatitis if the value was $\geq 3$ times the upper normal limit (ULN).

Urine trypsinogen 2 dipstick test works on the principle of immunochromatographic measurement of trypsinogen-2. The test strip is dipped into the patient's urine for 20 seconds within 10 minutes of collection and read after keeping for 5 minutes at room temperature. After the test strip has been dipped into the urine sample, trypsinogen-2 is bound to monoclonal-antibody-labeled blue latex particles, which then migrate across a nitrocellulose membrane to a zone containing another antibody specific for a different epitope on trypsinogen-2. The detection limit of the test for urine trypsinogen 2 was approximately $50 \mu \mathrm{g} / \mathrm{L}$. Hence, in the presence of excess urinary trypsinogen 2 $(>50 \mu \mathrm{g} / \mathrm{L})$ results in the appearance of 2 blue stripes, indicating a positive result; a negative result is demonstrated by only one blue stripe - the control stripe. No stripes on dipstick suggests an invalid test, in which case the test was repeated with new dipstick (Fig.1).

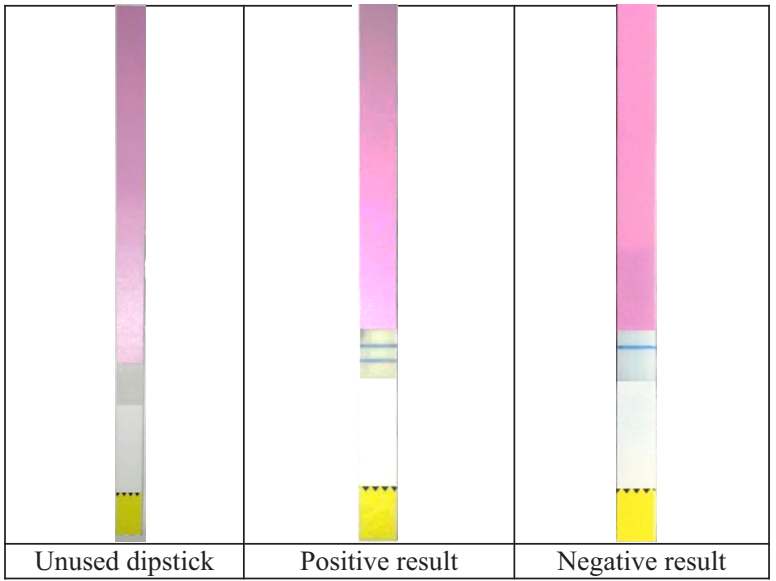

Fig.1 shows the various interpretations of dipstick.

The performance of Urine trypsinogen dipstick test with regard to its sensitivity, specificity, positive predictive value and negative predictive value, in comparison to serum amylase, serum lipase and imaging modalities have also been evaluated.

The sensitivity, specificity, positive predictive value and negative predictive values of the tests are reported. All the analysis was done using SPSS version 20 and Open Epi version 3.01

\section{RESULTS:}

Of the 50 patients included in the study, 37 patients ( 4 women and 33 men; mean age:37.2+/-11.2years) were diagnosed with acute pancreatitis by conventional methods. Rest of the 13 patients (1 women and 12 men; mean age:43+/-14.2years) were diagnosed as Hollow viscus perforation, Acute cholecystitis, Distal CBD stricture with mild cholangitis, Alcoholic gastritis, Splenic abscess and Mesenteric ischemia(Fig.1\&2). In the 37 patients diagnosed to have acute pancreatitis, etiology was Alcohol in 30, Gallstones in 4, Autoimmune, Post-Endoscopic retrograde cholangiopancreatography and Trauma in one case each. (Fig.3).

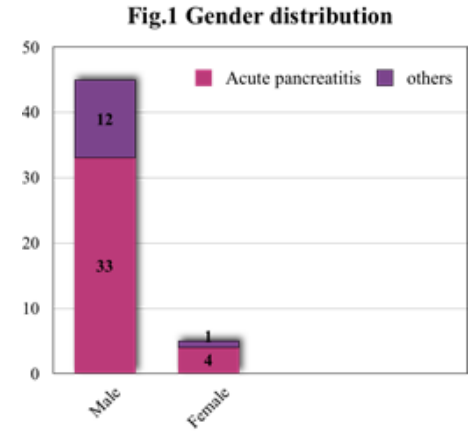

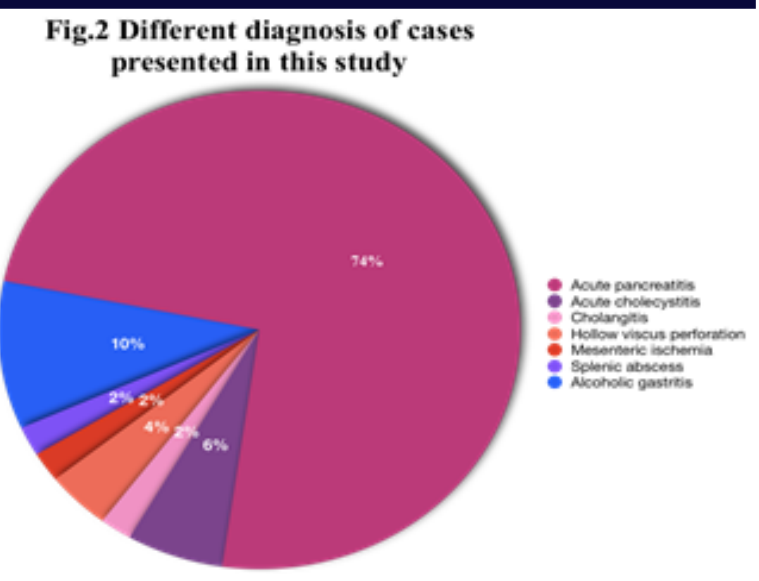

Fig.3 Various etiologies of acute pancreatitis in this study

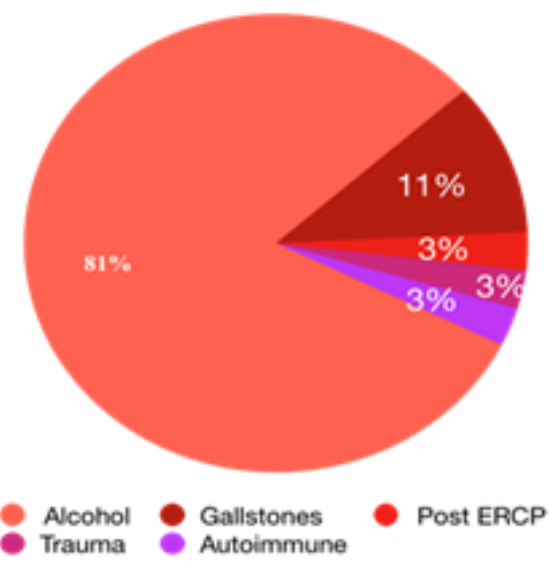

Fig.4 . Urine trypsinogen 2 dipstick test results in this study 40

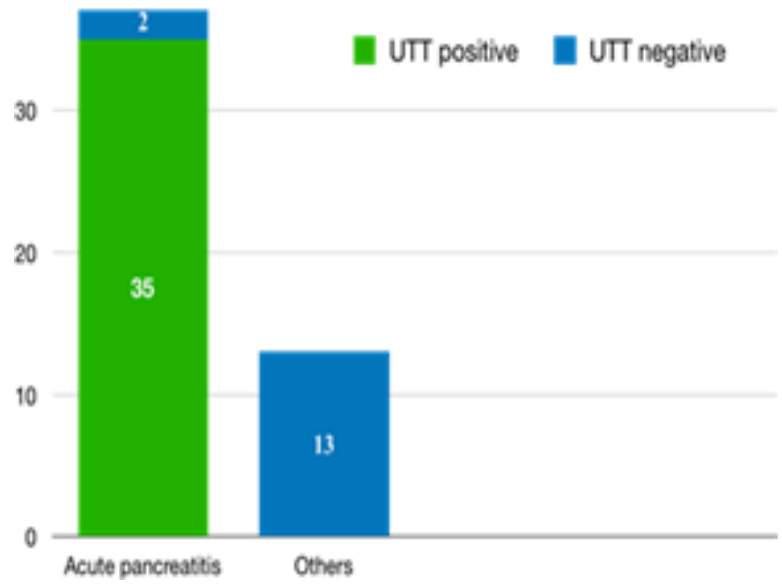

Urine trypsinogen 2 dipstick test was found positive in 35 (94.6\%) of 37 patients with diagnosis of acute pancreatitis and detected negative in rest of the two $(5.4 \%)$ patients. The test was negative in all 13 patients of control group diagnosed with other causes of acute abdomen (Fig.4)

The specificity, sensitivity, positive predictive value, negative predictive value, diagnostic accuracy of urine trypsinogen 2 dipstick test in this study was $100 \%, 94.59 \%, 100 \%, 86.67 \%, 96 \%$ respectively using Fisher's exact test and $p$ value is $<0.001$.

The diagnostic values of the urinary trypsinogen- 2 test, serum amylase, serum lipase, ultrasonography of abdomen, CECT abdomen for acute pancreatitis are compared in Table.1. 
Table.1. Comparison of diagnostic accuracy of different tests in this study

\begin{tabular}{|c|c|c|c|c|}
\hline Test & Specificity & Sensitivity & $\begin{array}{c}\text { Positive } \\
\text { predictive value }\end{array}$ & $\begin{array}{c}\text { Negative } \\
\text { predictive value }\end{array}$ \\
\hline UTT & $100 \%$ & $94.6 \%$ & $100 \%$ & $86.6 \%$ \\
\hline Serum amylase & $100 \%$ & $54.05 \%$ & $100 \%$ & $43.3 \%$ \\
\hline Serum lipase & $92.3 \%$ & $64.86 \%$ & $96 \%$ & $48 \%$ \\
\hline $\begin{array}{c}\text { Ultrasonography } \\
\text { abdomen }\end{array}$ & $100 \%$ & $43.24 \%$ & $100 \%$ & $38.24 \%$ \\
\hline CECT Abdomen & $100 \%$ & $100 \%$ & $100 \%$ & $100 \%$ \\
\hline
\end{tabular}

\section{DISCUSSION:}

Acute pancreatitis continues to be a diagnostic and therapeutic challenge in a emergency setup due to lack of a single pathognomonic laboratory test or clinical sign diagnosing the underlying pathology with rapidity and accuracy, ${ }^{4,5}$. It is expected that early diagnosis and therapy will improve outcomes. Early (within first 24 hours) aggressive fluid resuscitation is recommended by clinical practice guidelines irrespective of the etiology and is a cornerstone of the initial management of acute pancreatitis ${ }^{7-10}$. For instituting this early fluid therapy, the diagnosis of acute pancreatitis needs to be confirmed at the earliest. However, it is still a challenge to make a diagnosis in patients presented to an emergency setup where laboratory testing is not immediately available. Therefore, development of a rapid, simple, reliable diagnostic test with high accuracy is important.

Serum amylase and lipase are the most common laboratory markers used to establish the diagnosis of acute pancreatitis. But they can be nonspecific, depending on the time since onset of pain, other intraabdominal processes, and concomitant chronic diseases such as renal insufficiency ${ }^{4,11}$. In acute pancreatitis, serum amylase levels increase within 2-12 hours and return to normal range within a week, while serum lipase levels increase within 4-8 hours and remain elevated for 2 weeks but the urinary trypsinogen- 2 levels can remain elevated up to 30 days $^{13}$. CECT abdomen is the most accurate method for diagnosing and assessing the severity of acute pancreatitis, but it has its own limitations due to its cost, limited availability and potential side effects of the contrast material, and radiation exposure ${ }^{5}$.

Based on the sensitivity and specificity observed in different studies, which evaluated the utility of Urine trypsinogen 2 dipstick test in diagnosing acute pancreatitis shows that this test was comparable to serum amylase and lipase measurements in terms of specificity, sensitivity and diagnostic accuracy ${ }^{6,12-20}$.

\begin{tabular}{|c|c|c|}
\hline \multicolumn{2}{|c|}{ Table 2. Studies that have evaluated urinary trypsinogen-2 (UTT) performance. } \\
\hline Study & Sensitivity & Specificity \\
\hline Kemppainen et al & $94 \%$ & $95 \%$ \\
\hline Kylänpää-Bäck et al & $96 \%$ & $92 \%$ \\
\hline Lempinen et al & $62 \%$ & $87 \%$ \\
\hline Pezzilli et al & $53.3 \%$ & $100 \%$ \\
\hline Chen et al & $89.6 \%$ & $85.7 \%$ \\
\hline Jang et al & $100 \%$ & $96 \%$ \\
\hline Kamer et al & $91 \%$ & $72 \%$ \\
\hline Hwang et al & $72 \%$ & $92 \%$ \\
\hline This study & $94.6 \%$ & $100 \%$ \\
\hline
\end{tabular}

The Specificity and Sensitivity of urine trypsinogen 2 dipstick test in diagnosing acute pancreatitis in our study comprising heterogenous group of population attending the emergency department of a tertiary care hospital in southern India were $100 \%$ and $94.6 \%$ respectively and this is consistent with the literature as shown in Table. 2

Kemppainen et al, shown that the sensitivity of the Urine trypsinogen 2 dipstick test was superior to that of serum amylase and a negative result rules out acute pancreatitis with a high probability, while a positive result identifies patients in need of further evaluation ${ }^{6}$. Kylänpää-Bäck et al, reported that the negative predictive value of the urinary trypsinogen- 2 test strip was $99 \%$, hence the test is better suited for screening of acute pancreatitis compared to serum lipase ${ }^{12}$.

The two false negatives occurred in the study may be due to delay in the time of admission in relation to the onset of symptoms as shown in literature ${ }^{12,13,16}$.
In our study, the diagnostic accuracy of the urinary trypsinogen-2 dipstick test, serum amylase, and serum lipase was $96 \%, 66 \%$, and $72 \%$, respectively, for diagnosing acute pancreatitis in patients with acute abdominal pain. Hence, the urinary trypsinogen- 2 dipstick test with better diagnostic accuracy than serum amylase and lipase in diagnosing acute pancreatitis, suggests it may be a useful screening test for pancreatitis in emergency setup.

When compared with imaging studies, Jang et al showed that if the urine trypsinogen 2 dipstick test found to be accurate in a larger sample, it may decrease the need for computed tomography in early diagnosis of acute pancreatitis ${ }^{17}$. In our study, urine trypsinogen 2 dipstick test showed a better diagnostic accuracy than ultrasonography but inferior to computed tomography which is the gold standard for diagnosing and assessing the severity of pancreatitis.

Imaging studies have their own limitations in diagnosing acute pancreatitis in emergency setup such as ultrasonography is operator dependent, requires a skilled personnel. The computed tomography on the other hand suffers its own demerits such as cost, availability, requirement of skilled personnel, radiation exposure, and inadequate evaluation in patients with conditions contraindicating the contrast administration ${ }^{5}$.

The advantages of urine trypsinogen 2 dipstick test are non-invasive, and rapid. The results are objective, reproducible and reliable. It does not require laboratory facilities and can be performed almost instantaneously with results available within 5-6 minutes.

The limitations of the study were its single-centre design and small number of patients. Being an observational study, the investigations compared in the study were not controlled with respect to their timing of admission in relation to onset of symptoms.

\section{CONCLUSION:}

The urinary trypsinogen-2 dipstick test has proven to be a reliable and rapid test in screening of acute pancreatitis in emergency setup. This study shows that the dipstick test has high diagnostic accuracy and can be considered for regular use for diagnosing pancreatitis with the conventional methods. The urinary trypsinogen-2 test can also be performed in health care units where laboratory testing is not immediately available.

\section{Source of funding}

None

\section{Ethical clearance}

Obtained from Institutional Ethics Committee

\section{Conflict of interest}

The authors declare no conflict of interest.

\section{REFERENCES:}

1. Banks PA, Bollen TL, Dervenis C, Gooszen HG, Johnson CD, Sarr MG, Tsiotos GG, Vege SS. Classification of acute pancreatitis-2012: revision of the Atlant classification and definitions by international consensus. Gut. $2013 \mathrm{Jan}$ 1;62(1):102-11.

2. Hamada S, Masamune A, Kikuta K, Hirota M, Tsuji I, Shimosegawa T, Research Committee of Intractable Diseases of the Pancreas. Nationwide epidemiological survey of acute pancreatitis in Japan. Pancreas. 2014 Nov 1;43(8):1244-8.

3. Sarr MG. 2012 revision of the Atlanta classification of acute pancreatitis. Pol Arch Med Wewn. 2013 Jan 1;123(3):118-24.

4. Treacy J, Williams A, Bais R, Willson K, Worthley C, Reece J, Bessell J, Thomas D. Evaluation of amylase and lipase in the diagnosis of acute pancreatitis. ANZ journal of surgery. 2001 Oct; 71(10):577-82

5. London NJ, Neoptolemos JP, Lavelle J, Bailey I, James D. Contrast-enhanced abdominal computed tomography scanning and prediction of severity of acute pancreatitis: a prospective study. British journal of surgery. 1989 Mar; 76(3):268-72.

6. Kemppainen EA, Hedström JI, Puolakkainen PA, Sainio VS, Haapiainen RK, Perhonieni $\mathrm{O}$, Os trypsinogen-2 as a screening test for acu medicine. 1997 Jun $19 ; 336(25): 1788-93$.

7. Besselink M, van Santvoort H, Freeman M, Gardner T, Mayerle J, Vege SS, Werner J, Banks P, McKay C, Fernandez-del Castillo C, French J. IAP/APA evidence-based guidelines for the management of acute pancreatitis. Pancreatology. 2013;13(4, supp 2):E1-5.

8. Tenner S, Baillie J, DeWitt J, Vege SS. American College of Gastroenterology guideline: management of acute pancreatitis. American Journal of Gastroenterology. 2013 Sep $1 ; 108(9): 1400-15$

9. Fisher JM, Gardner TB. The "golden hours" of management in acute pancreatitis American Journal of Gastroenterology. 2012 Aug 1;107(8):1146-50.

10. Zarnescu NO, Barbu ST, Zarnescu EC, Costea R, Neagu S. Management of acute pancreatitis in the early stage. Maedica. $2015 \mathrm{Sep} ; 10(3): 257$.

11. Clavien PA, Robert J, Meyer PI, Borst FR, Hauser HE, Herrmann F, Dunand VI, Rohne $\mathrm{AD}$. Acute pancreatitis and normoamylasemia. Not an uncommon combination. Annals of surgery. $1989 \mathrm{Nov} ; 210(5): 614$.

12. Kylänpää-Bäck ML, Kemppainen E, Puolakkainen P, Hedström J, Haapiainen R, 
Perhoniemi V, Kivilaakso E, Korvuo A, Stenman UH. Reliable screening for acute pancreatitis with rapid urine trypsinogen-2 test strip. British journal of surgery. 2000 Jan; $87(1): 49-52$

13. Pezzilli R, Morselli-Labate AM, d'Alessandro A, Barakat B. Time-course and clinical value of the urine trypsinogen-2 dipstick test in acute pancreatitis. European journal of gastroenterology \& hepatology. 2001 Mar 1;13(3):269-74

14. Lempinen M, Kylänpää-Bäck ML, Stenman UH, Puolakkainen P, Haapiainen R, Finne P, Korvuo A, Kemppainen E. Predicting the severity of acute pancreatitis by rapid measurement of trypsinogen-2 in urine. Clinical chemistry. 2001 Dec 1;47(12):2103-7.

15. Hwang SJ, Chung JP, Kim YG, Song DH, Lee JS, Baek SS, Kim DY, Lee DY, Jeong YS, Ji SW, Lee SJ. Usefulness of urinary trypsinogen-2 dipstick test for diagnosis of acute
pancreatitis. The Korean journal of gastroenterology= TaehanSohwagiHakhoe chi. pancreatitis. The Korean journal of gastroenterology= TaehanSohwagiHakhoe chi.

16. Chen YT, Chen CC, Wang SS, Chang FY, Lee SD. Rapid urinary trypsinogen-2 test strip in the diagnosis of acute pancreatitis. Pancreas. $2005 \mathrm{Apr}$ 1;30(3):243-7.

17. Jang T, Uzbielo A, Sineff S, Naunheim R, Scott MG, Lewis LM. Point-of-care Urine Trypsinogen Testing for the Diagnosis of Pancreatitis. Academic Emergency Medicine. $2007 \mathrm{Jan} ; 14(1): 29-34$

18. Ali M, Mehsam S, Hussain A, Rasul S, Parveen S, Memon A, Aziz PA, Ali H. Frequency of Raised Urinary Trypsinogen-2 in Acute Pancreatitis.

19. Chien NH, Hung CS, Lee CL, Wu CH. Rapid urine trypsinogen-2 test for the early Chien detection of pancreatitis in endoscopic sphincterotomy patients. JOP. J Pancreas. 2016 May 1;17(3):284-8.

20. Kamer E, Unalp HR, Derici H, Tansug T, Onal MA. Early diagnosis and prediction of severity in acute pancreatitis using the urine trypsinogen-2 dipstick test: a prospective study. World Journal of Gastroenterology: WJG. 2007 Dec 14;13(46):6208. 